\title{
REFLEXÕES SOBRE O PROCESSO DE LUTO DE FAMILIARES EM TEMPOS DE PANDEMIA: UMA REVISÃO DE LITERATURA
}

\author{
Eliane Borges Rodrigues ${ }^{1}$; Tais Barcellos de Pellegrini ${ }^{2}$
}

\section{RESUMO}

Com as altas taxas de mortalidade relacionadas à pandemia da Covid-19, percebese a necessidade de atentar para o cuidado acerca dos processos de luto frente à perda afetiva causada pela morte de um familiar. O presente estudo trata-se de uma revisão bibliográfica da literatura nacional, que teve por objetivo compreender como se dá o processo de luto de familiares que perderam algum familiar devido a Covid19. Observou-se a escassez de estudos que abordam a temática dos processos de luto em tempos de pandemia, mas, ao mesmo tempo, percebeu-se a preocupação dos pesquisadores em fornecer orientação e esclarecimento nos diversos aspectos da vida que a Covid-19 afetou. Constatou-se que os rituais de despedida e o apoio psicológico são relevantes para que esses processos se deem dentro da normalidade, bem como é necessária uma ação multidisciplinar para o enfrentamento das sequelas físicas e psicológicas deixadas pela Covid-19. As reformulações nos rituais de despedida foram uma forma possitiva de enfrentar o luto. Mesmo assim, é importante encontrar outros meios para diminuir o sofrimento mental e prevenir o desenvolvimento do luto patológico.

Palavras-chave: Covid-19, hospital, familiares, luto.

Eixo Temático: Atenção Integral e Promoção à Saúde.

\section{INTRODUÇÃO}

O coronavírus (Covid-19) é uma doença respiratória infecciosa causada pelo novo Coronavírus (SARS-CoV-2) que foi disseminada pessoa por pessoa ao apresentarem um quadro clínico variável de infecções assintomáticas e quadros

\footnotetext{
${ }^{1}$ Eliane Borges Rodrigues - Psicóloga, e-mail: elianebufn@gmail.com

${ }^{2}$ Tais Barcellos de Pellegrini - Universidade Federal de Santa Maria, UFSM, e-mail: taisbpellegrini@gmail.com
} 
graves que requerem internação hospitalar nos casos que apresentam dificuldades respiratórias graves (BRASIL, 2020.)

A pandemia da Covid-19 trouxe consequências negativas na vida de muitas pessoas. O aumento dos índices de internações em Unidades de Terapia Intensiva (UTIs) e os inúmeros casos de mortes confirmadas em decorrência ao vírus foram algumas dessas consequências descritas pela Organização Mundial da Saúde, OMS (BRASIL, 2020). Isso vem impactando radicalmente as pessoas no que tange aos aspectos socioemocionais, decorrentes do sofrimento psíquico de quem foi acometido pela doença da Covid-19, assim como o medo da proximidade da morte, do contágio e vivência de sofrimento dos familiares, que precisam se manter afastados, tendo seu direito de acompanhante restringido ou suspenso como forma de contenção da epidemia e a iminência da morte de seu familiar.

Essas questões envolvem doença, morte, luto, sofrimento físico e psíquico, afetando diversos papéis familiares da sociedade. Dentro dessa realidade, infelizmente, muitas famílias têm de lidar com a perda e/ou luto de seus familiares e/ou amigos. Há casos de diversas famílias que perdem seus familiares, dando o último adeus de forma rápida, simples e a distância, como a filha que teve o apoio do profissional enfermeiro de um hospital da cidade do Rio de Janeiro onde a mãe estava internada para tratar a Covid-19 e deu o último adeus, por meio do celular sem poder vivenciar o ritual de despedida como gostaria, o que torna ainda mais dolorosa a experiência da perda (ROCHA, 2020).

Sabe-se que a morte é um fenômeno natural, porém aceitá-la ainda é um processo doloroso e difícil. Batista (2015) define o luto como um processo de reação frente a uma perda significativa que é formado por um segmento de quadros clínicos nos campos físicos, cognitivos, emocionais, sociais e espirituais que se misturam, processos psíquicos que o sujeito é intimado a enfrentar, que vão se atenuando progressivamente e que são necessários para refazer a vida. Assim, esses processos de morte e luto vêm sendo afetados pela pandemia devido à falta dos rituais de despedida (BATISTA, 2015).

Tamanha é a importância dos rituais fúnebres para que o familiar possa reorganizar o luto, que, em tempos de pandemia, estão sendo propostas outras 
formas de despedida, mediadas pela tecnologia, conforme orientação da OMS (FUNDAÇÃO OSWALDO CRUZ, 2020, 2020). Por intermédio de chamadas de vídeo, familiares se reúnem para uma última homenagem, realizam cultos e missas virtuais, realizam homenagens por meio de fotos e músicas como forma de expressar o luto para, assim, ressignificar a perda do ente querido (PERES; LAVOR, 2020).

Diante dessa problemática vivida na pandemia da Covid-19, as pessoas podem vivenciar dificuldades de aceitação da morte e gerar o que se chama de luto complicado ou luto traumático. Certamente, estas são questões que causam impactos negativos que podem afetar a sociedade. Para tanto, pesquisas sobre o efeito da pandemia da Covid-19 são de extrema relevância. Todas essas questões poderão se tornar um problema de saúde pública, pois há a tendência de aumento dos índices de doenças mentais em decorrência da pandemia da Covid-19 e necessidade de implementação de medidas e/ou estratégias a fim de cuidar e tratar dessas questões.

Para tanto este estudo teve como objetivo compreender como se dá o processo de luto de familiares que perderam algum familiar devido a Covid-19, através de uma revisão bibliográfica de literatura.

\section{METODOLOGIA}

A revisão bibliográfica da literatura, dentre as inúmeras vias de reflexão sobre a produção do saber, busca explicar um tema a partir de referências publicadas em materiais científicos nacionais em meios físicos e digitais (GIL, 2010).

Com a análise de dados encontrados e a partir das ideias centrais dos artigos pesquisados e do agrupamento dessas ideias, elencaram-se três temas: 1) família e doença, 2) hospital e Covid-19, 3) morte e luto, que foram descritos e fundamentados neste estudo na tentativa de entender e descrever como foram vivenciados os processos de luto pelos familiares que perderam alguém que foi acometido pela Covid-19 (CRESWRELL, 2010). Os referidos temas serão abordados e descritos a seguir. 


\section{RESULTADOS E DISCUSSÕES}

\section{A Família e a doença}

A família é um sistema no qual se dão as relações entre os seus componentes e, quando a doença da Covid-19 acomete um dos membros, gerando a internação em UTI, os familiares podem vivenciar essa situação de forma estressante, causando sofrimento emocional a toda a família. Muitos são acometidos pela ansiedade, estresse, negação, medo, desespero pela falta de controle da situação e separação do parente, a falta ou demora na informação sobre seu estado de saúde, além do constante medo da morte. Isso faz com que esse período se torne ainda mais difícil de ser superado e cause, muitas vezes, sofrimento psíquico (HABERKOM, 2004).

Diante disso, o acompanhamento familiar pode trazer benefícios tanto para o paciente, que se sente tranquilizado, não se sentindo sozinho e desamparado em um momento de fragilidade, como para o próprio familiar, que, ao observar a assistência médica e a evolução clínica do seu parente, tem seus níveis de ansiedade normalizados (LUCCHESE, 2012).

Sabe-se que é direito do paciente a participação da família no processo de saúde e de doença, assim como a informação acerca do estado de saúde do paciente é um direito da família que precisa ser atendido (MUNIZ, 2018). Recebendo essas informações, os familiares mantêm sua capacidade de receber e de compreender informações importantes, adquirindo confiança na equipe médica, o que favorece a comunicação entre familiar, que passa a se sentir seguro de que o paciente está tendo o melhor tratamento possível, e a equipe médica (LUCCHESE, 2012).

Com a pandemia da Covid-19 e tendo o objetivo de garantir segurança no atendimento aos pacientes, a integridade dos acompanhantes, visitantes e trabalhadores do serviço de saúde, bem como a prevenção de infecções, o Ministério da Saúde orienta que, nos serviços de saúde tidos como de referência ou retaguarda para atendimento aos pacientes acometidos com a doença, devem ser suspensas as visitas sociais a esses pacientes. Caso o serviço não tenha fluxo diferenciado para circulação dos demais pacientes e acompanhantes, recomenda-se 
a suspensão de todas as visitas (BRASIL, 2020). Nesse contexto, percebe-se uma via de mão dupla em que o membro familiar doente pode ser auxiliado pela família nos processos de adoecimento e recuperação, assim como a família pode vir a adoecer com a percepção dos processos de adoecimento e de finitude de seus membros e a falta de informações.

Entretanto, em uma pandemia como a atual, em que se somam todas essas questões de adoecimento, de distanciamento social com restrições de visitas e acompanhamento, carência de informações sobre os entes adoecidos, e porque a Covid-19 ainda é uma doença pouco conhecida, faz-se necessário pesquisar mais sobre essa problemática.

\section{Hospital e a COVID-19}

A pandemia levou os hospitais a se reformularem rapidamente, e muitas mudanças ocorreram nas unidades de referência para o tratamento da Covid-19. Foram implementadas medidas de higiene e proteção, como o uso de máscaras, o isolamento ou distanciamento social, a suspensão de acompanhantes para os pacientes internados nos hospitais (TEIXEIRA et al., 2020). Essas alternativas de enfrentamento trouxeram outras demandas, como estresse, ansiedade e depressão nos hospitais, tanto para profissionais da área da saúde como para familiares e pacientes que tiveram de se adequar à nova realidade da pandemia.

Os profissionais da área da saúde nos hospitais sentiram a quebra do vínculo dos pacientes que ficavam isolados de tudo e de todos e criaram uma forma de acolhimento entre pacientes e familiares, que foi a utilização de aparelhos eletrônicos com fins de comunicação (PERES; LAVOR, 2020). A exemplo disso, citase o recurso do Hospital de Clínicas da Unicamp em Campinas/SP, que utilizou o tempo de espera pelo boletim médico para favorecer a comunicação entre familiares e paciente. Desse modo, estes poderiam serem acolhidos em seu sofrimento emocional por meio da disponibilização, por parte da equipe, de lápis e papel para que os parentes escrevessem cartas que seriam lidas pelos profissionais da saúde aos pacientes internados em leitos ou até mesmo que tivessem intubados em UTIs (PERES; LAVOR, 2020). A implementação dessas estratégias para aumentar a 
interação entre paciente e familiares colaboram para melhorar a comunicação durante a pandemia e agem reduzindo a carga emocional dos familiares afetados pelo vírus, favorecendo, assim, a qualidade de vida dos envolvidos nessa problemática (INGRAVALLO, 2020).

Frente a essas questões, os hospitais instauraram estratégias de ações de humanização nos atendimentos que visam amenizar os sintomas e aliviar o sofrimento dos pacientes. Isso pode ser explicado a partir do início de flexibilizações, como o uso de aparelhos celulares, tabletes e computadores, a fim de proporcionar relações de afeto fortificadas, favorecer os laços afetivos, assim como contribuir com a saúde física e emocional do paciente (PERES; LAVOR, 2020). Sabendo da importância do suporte familiar, principalmente no momento do diagnóstico e tratamento, os hospitais de diversos países estão disponibilizando atendimento psicológico tanto aos pacientes como para seus familiares (CREPALDI et al., 2020).

No Brasil, o apoio psicológico aos pacientes já ocorre nos hospitais de forma breve e focal, porém, em tempos de pandemia, quando as angústias são potencializadas, o apoio psicológico foi estendido aos familiares de pessoas internadas com o vírus e àqueles que vieram a perder um ente querido para a Covid19 (VINHOTE, 2020).

O apoio psicológico durante a pandemia nos demais hospitais brasileiros também têm sido ofertados aos familiares via telefone. Nesses casos, os psicólogos do hospital informam-se sobre o estado clínico dos pacientes por meio do prontuário eletrônico e pareceres médicos e realizam suas intervenções com foco na ausência do parente, seja pela quarentena, seja pela morte do familiar (VINHOTE, 2020). Esse apoio tem sido ofertado gratuitamente por meio de parcerias e ações sociais em hospitais universitários tanto online, devido às restrições à presença de visitantes e acompanhantes como de forma presencial (MOREIRA, 2020).

Com toda essa demanda percebe-se que as mudanças nos hospitais se deram em vários aspectos, que vão desde questões de logística, com a necessidade de mais espaço, mais suprimentos e profissionais de diferentes áreas até a reformulação dos atendimentos do qual a tecnologia foi grande aliada. Intervenções e consultas médicas por teleconferência vêm sendo usadas como ferramenta para 
que a distância seja uma maneira de contenção e não um agravante no adoecimento, de forma que os familiares enlutados tenham apoio psicológico seguro em um momento tão difícil que é o luto.

\section{Morte e Luto}

A morte e o luto são experiências universais que geram medo e angústia. $O$ impacto da morte é brutal na vida do ser humano, a experiência da perda de um ente querido é uma das mais dolorosas vivências e a de mais difícil recuperação. Esta é uma experiência que causa dor, sofrimento e desorganização na vida de quem perdeu um parente, e o luto pode ocorrer de forma normal ou complicada, o que vai definir os fatores dessa diferenciação são as circunstâncias da morte (ABUD; ZIMMERMANN, 2012).

O luto é uma reação normal e esperada em resposta a um rompimento de vínculo, um processo de extrema importância para a elaboração de um luto normal é quando os familiares participam de rituais fúnebres, isto é, vêem o corpo do ente querido, participam do velório e das cerimônias religiosas, expressam sua dor e saudade (FUNDAÇÃO OSWALDO CRUZ, 2020).

No luto normal, a pessoa passa por etapas, como a negação, fase que não se aceita a morte; a fase da raiva, momento marcado por sentimento de culpa, medo, raiva e dor intensos, e a pessoa se sente injustiçada e revoltada com o mundo; a fase da barganha, em que a pessoa quer negociar com Deus, fazendo promessas para sair da situação; a fase da depressão, em que a pessoa se isola do mundo com sentimento de impotência; a fase da aceitação, aquela em que não há os sentimentos desesperadores e começa a enfrentar a realidade da perda (EZIRIK et al., 2018).

Sabe-se que a morte repentina é mais difícil de ser elaborada e pode causar consequências imediatas ou posteriores mais devastadoras do que no luto normal. $E$, quando não há a participação de rituais funerários ou de despedida, o processo fica comprometido, pois não se pode expressar ou compartilhar a dor com familiares e amigos e perde-se o contato com a realidade. Assim, sentimento de culpa e raiva são mais intensificados do que nas pessoas que podem participar desses rituais, o que vem a ser um fator contribuinte para o luto complicado (FUNDAÇÃO OSWALDO CRUZ, 2020). 
Esse processo de elaboração do luto fica prejudicado em tempos de pandemia, pois o Ministério da Saúde divulgou uma série de recomendações para o manejo dos corpos de pessoas faleceram por complicações decorrentes da Covid19. Visando garantir a segurança de profissionais, familiares e demais envolvidos, os velórios e funerais, no caso de pessoas falecidas com confirmação ou com suspeita de Covid-19, não são recomendados, portanto, os caixões são lacrados e muitas vezes não se pôde dar o último adeus como os familiares gostariam (CREMERS, 2020).

"O luto não é um obstáculo a ser superado; o luto é para ser vivido" (FRANCO, 2020). Assim, de acordo com a autora, a dor da perda é imensurável, mas deve ser vivida por meio da dor do luto, porém, com o distanciamento social causado pela pandemia, o afastamento do familiar doente nos últimos dias de vida no hospital, a falta de acompanhamento da família nesses últimos dias, as restrições a velórios e enterros e a ausência de rituais de despedidas alteram o processo de construção de sentidos em torno da compreensão da morte de um parente.

Para que os processos de luto sejam bem-sucedidos, eles devem ocorrer pelo reconhecimento da morte, e isso se dá com os processos de finitude nos rituais fúnebres, nos quais o funeral é importante por proporcionar a demonstração e o compartilhamento do sofrimento pela perda do ente querido para que, assim, seja possível dar continuidade à vida (FRANCO, 2020).

O não entendimento de finitude e a ressignificação da vida são processos afetados pela falta de um velório, o mínimo de pessoas permitidas e o tempo reduzido dos velórios, a obrigatoriedade de caixões lacrados, a falta de um corpo para ser contemplado pela última vez dando materialidade à morte e a prova de que foi sepultada a pessoa certa fazem com que o ritual seja incompleto, o que dificulta a elaboração do luto (CREPALDI, 2020).

Com o intuito de ajudar a superar a dor das perdas pela Covid-19, os rituais estão passando por transformações em todo o mundo. Na Espanha, estão usando alternativas, como um minuto de silêncio, bandeiras hasteadas a meio mastro, saudação de policiais a veículos que transportam falecidos, e, na Holanda, cerimônias estão sendo realizadas posteriormente ao sepultamento (CREPALDI, 
2020). Outra forma de amparar os familiares na reformulação desses rituais é o uso da tecnologia, assim, sentimentos de luto vêm sendo externalizados nas redes sociais como ferramenta para homenagear entes queridos.

As redes sociais estão sendo usadas para divulgar o óbito ou funeral. Nesses meios são postadas fotos para fazer homenagens e receber manifestações de apoio, formando uma rede socioafetiva quando o distanciamento não permite o contato físico. Entre as estratégias de apoio realizadas de forma virtual que estão permitindo aos familiares vivenciar o luto estão: inserir fotos sobre o caixão, proferir homenagens escritas ou verbais, cantar músicas significativas, acender velas nas janelas, realizar ligações telefônicas, passar mensagens de texto ou áudio, criar um memorial online onde se possa receber apoio, condolências e compartilhar pensamentos sobre o falecido, realizar rituais religiosos (CREPALDI, 2020).

Ao revisar a literatura, constatou-se a escassez de publicações científicas que abordam a temática dos processos de luto em tempos de pandemia. Por outro lado, percebeu-se que há interesse e preocupação de pesquisadores em contribuir com orientação e esclarecimentos nos diversos aspectos da vida que a Covid-19 afetou. Essa constatação deve-se às inúmeras publicações encontradas sobre diversidades de assuntos em tempos de pandemia sendo confirmada e explicada não pela falta de preocupação com a temática e sim por ser uma problemática recente onde estudos podem estar em processo (SUNDE e SUNDE, 2020).

No que se refere à morte e ao luto, os trabalhos pesquisados foram unânimes no que ser refere à importância dos rituais de despedida e sua necessidade de reformulação para que as pessoas que perderam um ente querido devido a complicações da Covid-19 possam vivenciá-los sem desenvolver o luto patológico. Nesse contexto, é importante o apoio psicológico, mesmo que de forma remota devido às restrições do isolamento social, para familiares que perderam um ou mais membros. Esse apoio psicológico é fundamental para auxiliar as pessoas enlutadas a lidarem com as perdas e vivenciarem os processos de luto naturalmente, sendo esta uma contribuição que o acompanhamento psicológico pode oferecer para o enfrentamento das consequências das perdas causadas pela doença da Covid-19 (NASCIMENTO et al, 2020). 


\section{QUFN}

\section{CONCLUSÃO}

As reformulações de morte e luto vão requerer mais atenção, novos cuidados e intervenções junto aos familiares de pessoas que perderam seus membros devido a complicações da Covid-19, pois é possível que alguns não consigam elaborar o luto e se adaptar bem às novas transformações frente às proibições de velórios e outros rituais de despedida. Nesses rituais, a dor da despedida pode ser, de certa forma, amenizada, assim como os impactos futuros causados pelo distanciamento.

É bastante provável que essa problemática traga consequências para a população em geral. Por isso, o tema aqui abordado merece estudo, investigação e investimento em Saúde mental, na área de políticas públicas, em que, atualmente, há precariedade de recursos financeiros, de estrutura e de pessoal. Assim, diante da atual realidade, é preciso ampliar espaços de suporte a enlutados.

Um aspecto positivo nesse contexto foi a criação de alternativas para a realização dos rituais de maneira humanizada e afetuosa diante desse momento difícil nas despedidas dos entes queridos. Essa foi uma forma benéfica de reinventar os ritos de despedida, o que propiciará a vivência do luto normal e a ressignificação da vida, a aceitação da morte de forma saudável.

A pandemia trouxe muitas mudanças na vida das pessoas, causando impactos significativos, causando necessidade de adaptações. Nesse âmbito, percebe-se a necessidade de programas de reabilitação pós Covid-19 que englobem as questões de saúde física e mental e que promovam apoio emocional, escuta e acompanhamento que fortaleçam as redes socioafetivas e favoreçam a promoção da saúde mental nesta fase em que as pessoas precisarão se readaptar e lidar com as perdas e transformações que foram consequências da pandemia. 


\section{REFERÊNCIAS}

BRASIL. Ministério da Saúde. Protocolo de Manejo Clínico da Covid-19 na Atenção Especializada. 1. ed. Brasília, DF, 2020. Disponível em: https://bvsms.saude.gov.br. Acesso em: 25 set. 2020.

BATISTA, Julio dos Santos. Laços no desenlace ou desenlace dos laços? Refletindo sobre o luto em UTIs. In: GUIMARÃES, Hélio Penna et al. Do nascimento à morte: novos caminhos na prática da psicologia hospitalar. Rio de Janeiro: Atheneu, 2015.

CRESWRELL, John W. Projeto de pesquisa: método qualitativo, quantitativo e misto. 3. ed. Porto Alegre: Artmed, 2010.

CREPALDI, Maria Aparecida et al. Terminalidade, morte e luto na pandemia da COVID-19: demandas psicológicas emergentes e implicações práticas. Estudos de Psicologia. Campinas. V. 38, 2021. ISSN 1982-0275 2020. Disponível em: https://www.scielo.br/j/estpsi/a/LRmfenxMXwrbCtWSxJKwBkm/?lang=pt. Acesso em: 6 maio, 2021.

CREMERS. Conselho Regional de Medicina do Rio Grande do Sul. Publica orientações para manejo de corpos durante a Covid-19. 1. ed. Brasília, DF, 2020. Disponível em: https://cremers.org.br/ministerio-da-saude-publica-orientacoes-paramanejo-de-corpos-durante-a-covid-19/. Acesso em: 26 set. 2020.

EIZIRIK, Claudio Laks et al. O ciclo da vida humana. In: BRASIL, Marco Antonio Alves et al. Psicologia Médica: a dimensão psicossocial da prática médica. Rio de Janeiro: Guanabara Koogan, 2018.

FUNDAÇÃO OSWALDO CRUZ. [2020?]. Saúde mental e atenção psicossocial na pandemia COVID-19: processo de luto no contexto da COVID-19. Disponível em: https://www.fiocruzbrasilia.fiocruz.br/wp-content/uploads/2020/04/Sa\%C3\%BAdeMental-e-Aten\%C3\%A7\%C3\%A3o-Psicossocial-na-Pandemia-Covid-19-processode-luto-no-contexto-da-Covid-19.pdf. Acesso em: 6 maio, 2021.

FRANCO, Maria Helena. Luto coletivo e a luta pela vida. In: ROCHA, Rogério Lannes. A dor da perda. Revista Radis, n. 214, p. 3, jul. 2020.

GIL, Antonio Carlos. Como elaborar um projeto de pesquisa. 5. ed. São Paulo: Atlas, 2010.

HABERKOM, Adriana. Atuação psicológica na UTI. In: BRUSCATO, Wilse, Laura et al. A prática da psicologia hospitalar na Santa Casa de São Paulo: novas páginas em uma antiga história. São Paulo: Casa do Psicólogo, 2004.

INGRAVALLO, Francesca. Morte na pandemia COVID-19. The Lancet Public Health, V. 5. P. 258, maio. 2020. Disponível em: 
https://www.sciencedirect.com/science/article/pii/S2468266720300797?via\%3Dihub. Acesso em: 6 maio, 2021.

LUCCHESE, Ana Cecilia. A família e o adoecer. In: MARCO, Mario Alfredo de et al. Psicologia médica: abordagem integral do processo saúde doença. Porto Alegre: Artmed, 2012.

MOREIRA, Giullia. Complexo hospitalar da UFPA oferece apoio psicológico durante pandemia da COVID-19. Universidade Federal do Pará, 2020. Disponível em: https://portal.ufpa.br/index.php/ultimas-noticias2/11503-complexo-hospitalar-daufpaoferece-apoio-psicologico-durante-pandemia-da-covid-19. Acesso em: 7maio, 2021.

MUNIZ, José Roberto. O médico, seu paciente e a família. In: BRASIL, Marco Antonio Alves et al. Psicologia Médica: a dimensão psicossocial da prática médica. Rio de Janeiro: Guanabara Koogan, 2018.

NASCIMENTO, Adriana Rodrigues et al. Rituais de despedida no contexto da pandemia da pandemia da covid-19. Cadernos Especiais. v. 14, n. 1, p.80-85, Jan/junh. 2020 ISSN: 1808-7329/1809-0893 Disponível em:

file:///C:/Users/8026/Downloads/angcp,+12+-+384+-+80+-+85.pdf. Acesso em: 25 de set. 2021

PERES, Ana Cláudia; LAVOR, Adriano de. Sobrevivência e o luto. In: ROCHA, Rogério Lannes. A dor da gente: o impacto nas famílias atingidas pela COVID-19.

Revista Radis, n. 214, p. 13-20, jul., 2020.

ROCHA, Rogério Lannes. Luto coletivo e luta pela vida. In: ROCHA, Rogério Lannes. A dor da gente: o impacto nas famílias atingidas pela COVID-19. Revista Radis, n. 214, p.13-20, jul., 2020.

SUNDE, Rosario Martinho; SUNDE, Lucildina Muzuri Conferso. Luto familiar em tempos da pandemia da covid-19: dor e sofrimento psicológico. Revista Interfaces. V.8 n.3, p. 703-710, 2020. ISSN 2317-434x. Disponível em:

file:///D:/_Usu\%C3\%A1rio/Downloads/787-2571-1-PB.pdf. Acesso em: 28 set., 2021.

TEIXEIRA, Carmem Fontes de Souza et al. A saúde dos profissionais da área da Saúde no enfrentamento da pandemia COVID 19. Revista Ciência e Saúde Coletiva, v. 25, n. 9, 2020. ISSN 1678-4561. Disponível em: https://www.scielo.br/scielo.php?pid=S1413-81232020000903465\&script=sci_arttext. Acesso em: 27 set. 2020.

VINHOTE, Ana Maria. Como o suporte psicológico ajuda no enfrentamento. Brasília, DF: Agência de Brasília, 2020. Disponível em: https://www.agenciabrasilia.df.gov.br/2020/05/17/como-o-suporte-psicologico-ajudano-enfrentamento/. Acesso em: 5 maio 2021. 